\title{
Corn Oil in Treatment of Ischaemic Heart Disease
}

\author{
G. A. ROSE,* D.M., M.R.C.P. ; W. B. THOMSON, $†$ M.D., M.R.C.P.; R. T. WILLIAMS, $\ddagger$ M.B., M.R.C.P.
}

Brit. med. F., 1965, 1, 1531-1533

It has been shown that ischaemic heart disease tends to be associated with elevated levels of serum cholesterol, both in populations (Keys et al., 1958) and in individuals (Kannel et al., 1961). There is also evidence that population levels of serum cholesterol are sometimes correlated with (among other characteristics) a high intake of animal fats and a relatively low intake of unsaturated vegetable oils (Bronte-Stewart et al., 1955). Attempts to demonstrate such a correlation in individuals between customary diet and serum-cholesterol level have been unsuccessful (Morris et al., 1963) ; but the level may be altered by changes in fat intake (Ahrens et al., 1955 ; Gordon and Brock, 1958 ; and Pilkington et al., 1960).

From this it has seemed worth investigating the effects on ischaemic heart disease of reducing the level of serum cholesterol. Adequately controlled therapeutic trials have been reported for cholesterol-lowering hormones (Stamler et al., 1960; Oliver and Boyd, 1961), with negative results. Nevertheless it is desirable to test the dietary hypothesis more directly. The results of prophylactic trials of this kind are unlikely to be available for some time. In the meantime it is of clinical interest to know whether patients with established ischaemic heart disease can be benefited by dietary manipulation. A simple reduction of fat intake has failed to show any benefit (Ball et al., 1964); but no adequately controlled "double-blind" trial of an unsaturated oil has yet been reported.

\section{Aims}

Our purpose was to study the effects of prescribing a vegetable oil and a restricted fat diet to patients with ischaemic heart disease. The primary interest was in an unsaturated oil with a cholesterol-lowering effect. But large doses of any oil may have secondary effects on diet and nutrition, so that differences between an unsaturated-oil group and a control group might be due to these secondary effects rather than to unsaturated fatty acids as such. It could, for example, be relevant that mortality from heart disease is low in Italy and Greece, whose inhabitants consume much olive oil ; this oil has no major effect on serumcholesterol level, its main fatty acid (oleic acid) being only mono-unsaturated. The trial was therefore designed to study the effects not only of a more highly unsaturated oil (corn oil) but also of olive oil. It seemed likely that if any differences emerged between the olive-oil and corn-oil groups these would reflect the specific effects of polyunsaturated fatty acids.

\section{Methods}

Patients were accepted for the trial who met the following criteria. (1) Either electrocardiographic evidence of infarction (abnormal Q/QS waves, or typical serial ST/T changes) or clear history of angina of effort, meeting World Health Organization precise criteria (Rose, 1962) with or without changes in the resting electrocardiogram, but without valvular disease, anaemia, or syphilis. (2) Age under 70 years.

\footnotetext{
* Senior Lecturer to the Medical Unit, St. Mary's Hospital, London. t Consultant Physician, High Wycombe Group Hospitals ; formerly Senior Registrar, St. Mary's Hospital, London.

¥ Consultant Physician, Crumpshall Hospital, Manchester ; formerly
} Registrar, St. Mary's Hospital, London.
(3) Absence of heart failure, and also of any non-cardiac disease likely to threaten life within two years. (4) Absence of personal or geographical factors likely to interfere with clinic attendance or the taking of oil.

When a new patient was accepted for the trial a sealed envelope was opened containing the allocation instructions. In the case of patients allocated to an oil group the instructions referred only to a code number. Thus the physicians in charge knew which patients were receiving oil, but they did not know until the end of the trial the kind of oil that they were receiving.

All patients received conventional treatments, at the discretion of the physicians. At the time when the trial started long-term anticoagulant therapy was seldom used. Later it became more popular, especially for patients suffering reinfarction. To avoid confusion by possible interactions between treatments a few patients already receiving this treatment were excluded from entry to the trial ; and in addition the occurrence of infarction after entry was taken as an endpoint, the patient being then withdrawn from the trial.

Patients in both oil groups were instructed to avoid fried foods, fatty meat, sausages, pastry, ice-cream, cheese, cakes (except plain sponge), etc. Milk, eggs, and butter were restricted. An oil supplement of $80 \mathrm{~g}$./day was prescribed, to be taken in three equal doses at meal-times. The general nature and purpose of treatment were explained, together with the fact that different patients were receiving different kinds of oil. No advice on dietary fat was give to control patients.

All patients attended a special follow-up clinic, initially at monthly intervals, and later every two months. Assessment was by standardized history, physical examination, and electrocardiography. The electrocardiograms were assessed without knowledge of the patient's treatment group. The trial was planned to cover three years' observation of each patient ; but by the end of two years only one-half of the patients remained in the trial, the rest being dead, removed for reinfarction, or lost to follow-up. Consequently the results for only the first two years will be reported here.

Fears have recently been expressed, both within the profession and outside it, that clinical trials may sometimes operate against the best interests of the patients. We would like to

TABLE I.-Characteristics of Patients at Entry to Trial in the Three

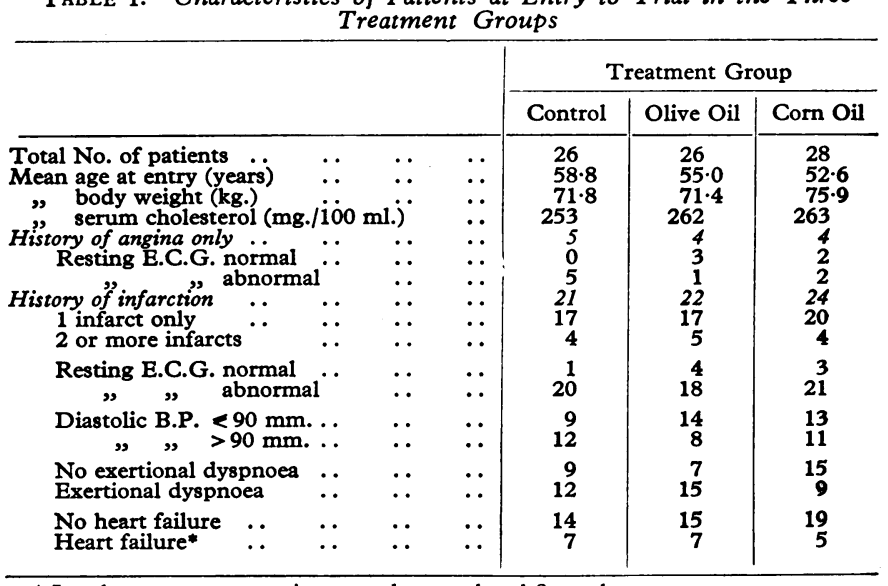

* Jugular venous congestion or oedema or basal fine rales. 
record our own experience of the reverse-namely, that the necessity in this trial for careful supervision and continuity of care resulted in unusually good doctor-patient relations and patient morale.

Eighty patients entered the trial. Thirty-one were known to have had an infarction within the previous month; in the remainder the disease was more stable. Some of the characteristics of patients in the three groups at the time of entering the trial are shown in Table I. There are no significant differences between the groups with regard to any of the characteristics listed ( $P$ in each case $>0.05$ ), and it seems likely that at the start of the trial the prognosis for each of the three groups was approximately similar.

\section{Results}

The prescribed dose of oil was $80 \mathrm{~g}$./day. But many found the treatment burdensome: distaste, nausea, and diarrhoea were the commonest complaints. An attempt was made to assess how much oil each patient actually took, based on the number of cans issued, the amounts left in the returned cans, and the patients' own statements. The results are indicated in Table II : they are, of course, maximum estimates. Patients in all three groups tended on average to lose a little weight as time went on. Unexpectedly, the average loss was greatest in the corn-oil group.

TABLE II.-Estimated Amounts of Oil Consumed by Patients at Different Stages of the Trial

\begin{tabular}{|c|c|c|c|c|c|c|c|}
\hline & & & & \multicolumn{2}{|c|}{ Olive Oil } & \multicolumn{2}{|c|}{ Corn Oil } \\
\hline \multicolumn{4}{|c|}{ Period } & $\begin{array}{l}\text { No. of } \\
\text { Patients }\end{array}$ & $\begin{array}{c}\text { g./day } \\
\text { (Average) }\end{array}$ & $\begin{array}{l}\text { No. of } \\
\text { Patients }\end{array}$ & $\begin{array}{l}\text { g./day } \\
\text { (Average) }\end{array}$ \\
\hline $\begin{array}{l}0-6 \text { months } \\
6-12 ", \\
12-18 \% \\
18-24 "\end{array}$ & $\begin{array}{l}\cdots \\
\cdots \\
\cdots\end{array}$ & $\begin{array}{l}\cdots \\
\cdots \\
\cdots\end{array}$ & $\begin{array}{l}\cdots \\
\cdots \\
\cdots\end{array}$ & $\begin{array}{l}24 \\
19 \\
16 \\
13\end{array}$ & $\begin{array}{l}73 \\
52 \\
47 \\
51\end{array}$ & $\begin{array}{l}28 \\
22 \\
19 \\
13\end{array}$ & $\begin{array}{l}74 \\
64 \\
62 \\
51\end{array}$ \\
\hline Mean & . & .. & .. & 一 & 58 & - & 64 \\
\hline
\end{tabular}

Dietary assessments were performed on those patients still in the trial during the second year of follow-up, using a selfadministered questionary (Keen and Rose, 1958). This method is appropriate for comparing the relative intakes of different groups, although the absolute levels may be misjudged. Table III shows the estimated averages. It is interesting to note the spontaneous adjustment of appetite in the two oil groups, whose mean daily calorie intakes were very similar to those of the control group.

TABle III.-Dietary Assessment During Second Year in Trial

\begin{tabular}{|c|c|c|c|c|c|c|c|c|}
\hline \multirow{2}{*}{\multicolumn{2}{|c|}{ Group }} & \multirow[b]{2}{*}{$\begin{array}{l}\text { No. of } \\
\text { Patients }\end{array}$} & \multicolumn{6}{|c|}{ Estimated Mean Daily Intake } \\
\hline & & & $\begin{array}{l}\text { Carbo- } \\
\text { Hydrate }\end{array}$ & Protein & Fat & Calories & $\begin{array}{l}\text { Calories } \\
\text { from Oil }\end{array}$ & $\begin{array}{c}\text { Total } \\
\text { Calories }\end{array}$ \\
\hline $\begin{array}{l}\text { Control } \\
\text { Olive oil } \\
\text { Corn oil }\end{array}$ & $\begin{array}{l}. . \\
\cdots\end{array}$ & $\begin{array}{l}16 \\
12 \\
15\end{array}$ & $\begin{array}{l}249 \\
216 \\
189\end{array}$ & $\begin{array}{l}64 \\
49 \\
57\end{array}$ & $\begin{array}{l}70 \\
45 \\
50\end{array}$ & $\begin{array}{l}1,933 \\
1,505 \\
1,475\end{array}$ & $\begin{array}{l}\text { c. } \overline{540} \\
\text { c. } 595\end{array}$ & $\begin{array}{r}1,933 \\
\text { c. } 2,045 \\
\text { c. } 2,070\end{array}$ \\
\hline
\end{tabular}

Serum-cholesterol values were measured at each visit by the method of Zak, Zlatkis, and Boyle (Henly, 1957). This method probably gives readings that are $18 \mathrm{mg} . / 100 \mathrm{ml}$. too high (G. R. Cooper, personal communication, 1964). Because of the large variation in absolute levels between patients the results (Table IV) have been related to the change observed in each patient from his or her own initial level. The mean values for control and olive-oil patients showed no significant change, although the administration of olive oil seems to have increased the variability of readings. The depressions seen in the corn-oil group are highly significant, except in the final period. (The latter seems to be a chance phenomenon, since among those who continued taking oil for a third year the level fell again.) The depressions represent the average over all patients, including some who probably took little or no corn oil.

TABIE IV - Changes in Serum-cholesterol Levels at Different Periods of the Trial, With Their Standard Errors and Significance Levels

\begin{tabular}{|c|c|c|c|c|c|c|}
\hline \multirow{2}{*}{$\begin{array}{c}\text { Period } \\
\text { (Months) }\end{array}$} & \multicolumn{2}{|l|}{ Control } & \multicolumn{2}{|l|}{ Olive Oil } & \multicolumn{2}{|l|}{ Corn Oil } \\
\hline & $\begin{array}{c}\text { Mean and S.E. } \\
\text { (mg./100 ml.) }\end{array}$ & $\mathbf{P}$ & $\begin{array}{l}\text { Mean and S.E. } \\
\text { (mg./100 ml.) }\end{array}$ & $\mathbf{P}$ & $\begin{array}{l}\text { Mean and S.E. } \\
\text { (mg./100 ml.) }\end{array}$ & $\mathbf{P}$ \\
\hline $\begin{aligned} 0-6 & \ldots \\
6-12 & \cdots \\
12-18 & \cdots \\
18-24 & \cdots\end{aligned}$ & $\begin{array}{l}+4.4( \pm 7 \cdot 2) \\
+0.3( \pm 9 \cdot 2) \\
-7.9( \pm 9.4) \\
-2.8( \pm 12.1)\end{array}$ & $\begin{array}{l}>0.5 \\
>0.8 \\
>0.4 \\
>0.8\end{array}$ & $\begin{array}{r}+3.5( \pm 9.2) \\
+12.0( \pm 17.5) \\
+4.0( \pm 20 \cdot 2) \\
-0.9( \pm 10.2)\end{array}$ & $\begin{array}{l}>0.7 \\
>0.4 \\
>0.6 \\
>0.8\end{array}$ & $\begin{array}{l}-25 \cdot 0( \pm 8 \cdot 8) \\
-30 \cdot 8( \pm 10.5) \\
-30 \cdot 3( \pm 9 \cdot 9) \\
-19 \cdot 9( \pm 13.5)\end{array}$ & $\begin{array}{l}<0.01 \\
<0.01 \\
<0.01 \\
<0.2\end{array}$ \\
\hline
\end{tabular}

Progress was measured according to five criteria. (1) Sudden death. (2) Fatal infarction. (3) Non-fatal infarction, diagnosed on the basis of a suggestive history, together with either S.G.O.T. level exceeding 40 units $/ \mathrm{ml}$. or electrocardiographic (E.C.G.) evidence of new $Q$ wave or typical ST elevation. (4) Non-fatal probable infarction, defined as central chest pain accompanied by E.C.G. evidence of new ST depression (Minnesota Code criteria IV 1-3, see Blackburn et al., 1960) or T-wave flattening or inversion (Minnesota Code criteria V 1-3). (5) Other significant cardiac pain, defined as central chest pain lasting one hour or more, unaccompanied by raised S.G.O.T. or by the E.C.G. changes specified in (3) or (4), or sudden worsening of angina of effort.

The first four of these categories are classed as " major cardiac events," and patients developing them were withdrawn from the trial. Patients developing "other significant cardiac pain" stayed in the trial.

Four patients were removed from the trial for other reasons. Two developed non-cardiac thromboembolism and were given anticoagulant therapy. The other two were removed because of diabetes mellitus. One of them already had mild diabetes, but glycosuria increased considerably soon after he started oil. Oil was stopped and glycosuria disappeared. Oil was restarted, but was stopped a month later because heavy glycosuria recurred. The other patient, not a previously recognized diabetic, developed glycosuria with a diabetic glucose-tolerance test a few weeks after starting oil. In addition to these withdrawals six patients were lost to follow-up.

The trial has been analysed in six-month periods (Table V). The state of the groups at the end of each period has been given

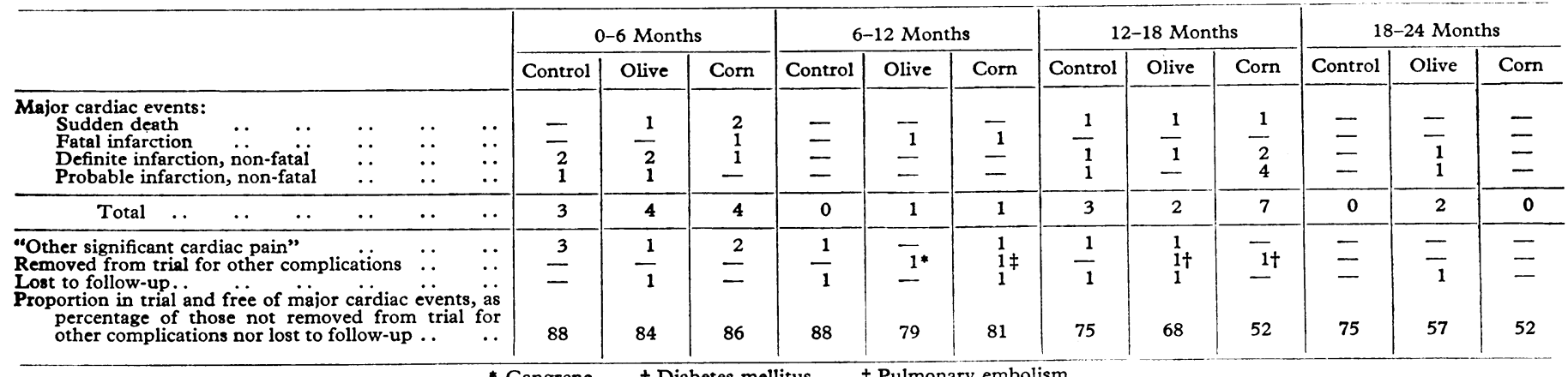


as the number of patients still in the trial and free of any " major cardiac event," expressed as a percentage of the total number in the trial at that point-that is, the number of starters less those removed for non-cardiac complications or lost to follow-up.

At two years the proportion of patients remaining free of major cardiac events is greater for the control group (75\%) than for the two oil groups (olive oil $57 \%$, corn oil $52 \%$ ). The likelihood that the difference between the control and corn-oil groups was due to chance is $0.05-0.1$ (S.E. of difference, $\pm 13 \%)$. Among those patients who were followed for a third year no new trend emerged.

\section{Conclusion}

The aim of the trial was not to duplicate the many carefully regulated laboratory studies of the effects of unsaturated oils on serum cholesterol. Rather was it aimed to study the feasibility and possible value of such regimes in a typical group of hospital coronary patients. Among such persons, and especially where treatment is prolonged, it is inevitable that some will comply incompletely or not at all. We estimated that initially the patients in the two oil groups took on average about $90 \%$ of the prescribed $80 \mathrm{~g}$./day; but after a year the estimated average intake fell to around $60 \%$ of the ideal. As a result the differences in serum-cholesterol levels between the two oil groups are less than would be predicted theoretically, although still highly significant. Such limitations may be unavoidable in a clinical trial of a rather unpleasant regime.

The patients receiving the key treatment (corn oil) fared worse than those in the other two groups: two years from the start of treatment infarction or death had occurred in onequarter more of the corn-oil than of the control group. This difference closely approaches the conventional significance level $(0.1>P>0.05)$. The probability that a true difference of the same magnitude but in the other direction may have been missed by chance is less than 1 in 1,000 . It is concluded that under the circumstances of this trial corn oil cannot be recommended as a treatment of ischaemic heart disease. It is most unlikely to be beneficial, and it is possibly harmful.

\section{Summary}

Eighty patients with ischaemic heart disease were allocated randomly to three treatment groups. The first was a control group. The second received a supplement of olive oil with restriction of animal fat. The third received corn oil with restriction of animal fat. The serum-cholesterol levels fell in the corn-oil group, but by the end of two years the proportions of patients remaining alive and free of reinfarction (fatal or non-fatal) were $75 \%, 57 \%$, and $52 \%$ in the three groups respectively. The likelihood that the worse experience of the patients treated with corn oil was due to chance alone was $0.05-0.1$. The likelihood that the trial failed by chance to detect a true and important benefit from corn oil was extremely remote. It is concluded that under the circumstances of this trial corn oil cannot be recommended in the treatment of ischaemic heart disease.

We are grateful to Professor W. S. Peart for advice and encouragement, to Paddington General Hospital for clinic facilities, and to physicians of St. Mary's and Paddington General Hospitals for referral of patients.

\section{REFERENCES}

Ahrens, E. H., Tsaltas, T. T., Hirsch, J., and Insull, W. (1955). f. clin.

Ball, K. P., McAllen, P. M., Pilkington, T. R. E., Sharland, D. E., Sowry, G. S. C., and Wilkinson, P. (1964). Proc. IV Europ. Congr.

Blackburdiol., H., Keys, A., Simonson, E., Rautaharju, P., and Punsar, S. (1960). Circulation, 21, 1160.

Bronte-Stewart, B., Keys, A., and Brock, J. F. (1955). Lancet, 2, 1103.

Gordon, H., and Brock, J. F. (1958). S. Afr. med. Ұ., 32, 397.

Henly, A. A. (1957). Analyst, 82, 286 .

Kannel, W. B., Dawber, T. R., Kagan, A., Revotskie, N., and Stokes, J. (1961). Ann. intern. Med., 55, 33 .

Keen, H., and Rose, G. A. (1958). Brit. med. 7., 1, 1508.

Keys, A., Kimura, N., Kusukawa, A., Bronte-Stewart, B., Larsen, N.,

and Keys, M. H. (1958). Ann. intern. Med., 48, 83. T. R. E. (1963). Brit. med. 7., 1, 571.

Oliver, M. F., and Boyd, G. S. (1961). Lancet, 2, 499.

Pilkington, T. R. E., Stafford, J. L., Hankin, V., S., Simmonds, F. M., and Koerselman, H. B. (1960). Brit. med. F., 1,'23.

Rose, G. A. (1962). Bull. W.ld Hith Org., 27, 645 .

Stamler, J., Katz, L. N., Pick, R Lewis, L. A., Page, I H Pick, A Kaplan, B. M., Berkson, D. M., and Century, D. F. (1960). Circulation, 22, 658 .

\title{
Carcinoid Syndrome Associated with Oat-cell Carcinoma of Bronchus
}

\author{
J. D. KINLOCH,* M.B., M.R.C.P.ED., M.R.C.P.GLASG. ; J. N. WEBB, † M.B., B.CHIR., D.OBST.R.C.O.G. ; \\ D. ECCLESTON, $\ddagger$ J. ZEITLIN, $\ddagger$
}

Brit. med. F., 1965, 1, 1533-1535

The remarkable potential of carcinomas of the bronchus to produce endocrine disorders, such as Cushing's syndrome (Brown, 1928), hyponatraemia (Winkler and Crankshaw, 1938), gynaecomastia (Hardy, 1960), and hypercalcaemia (Connor et al., 1956), is now well recognized. The most recent addition to this group of disorders is the carcinoid syndrome, and this is known to be associated with 5-hydroxytryptamine (5-H.T.) secretion (Williams and Azzopardi, 1960) and also with 5-hydroxytryptophan (5-H.T.P.) secretion (Gowenlock et al., 1964). However, 5-H.T. and its metabolites are probably not the direct mediators of carcinoid flushes, and the release of a kinin peptide from the tumour has recently been suggested as responsible (Oates et al., 1964).

We recently had the opportunity to study 5-H.T. metabolism and kinins in a patient with many features of the carcinoid syndrome who was ultimately shown to have an oat-cell carcinoma of the bronchus. As this association has only rarely been recognized and our ignorance of the mechanism responsible for the flushing in the carcinoid syndrome continues, it was thought that our investigations of a single patient would be of sufficient interest to justify a case report.

\section{Case Report}

A bus-conductor aged 43 was admitted to hospital with a history of upper abdominal discomfort, nausea, anorexia, and loss of weight for the previous three months; during the month preceding admis-

\footnotetext{
- Senior Registrar, Department of Endocrinology and Metabolic Diseases,
Western General Hospital, Edinburgh. †egistrar in Pathology, Western General Hospital, Edinburgh ₹ Research Fellow, Department of Pharmacology, University of Edlaburgh.
} 